\title{
Devingen Mizansenden Huzursuz Kameraya: Yeșilçam'da Zum
}

\author{
Çağrı İnceoğlu'
}

\begin{abstract}
öz
Zum mercek ile yapılan optik bir etki olan zum hareketi Yirminci Yüzyılın ilk yarısında ortaya çıkmış olmasına karşın, gelişimini ve yaygın kullanımını İkinci Dünya Savaşı sonrası televizyon yayıncılığının gelişmesiyle kazanmıştır. Zum hareketi zamanla sinemada da kullanım alanı bulmuştur. Batı sinemasında 1950'ler ve 1960'lardan itibaren özellikle bağımsız sinemacılar tarafından tercih edilmeye başlanmış estetik ve pratik bir araç olarak zumun sinemadaki yeri tartışmalara konu olmuştur. Türk sinemasında 1960'lı yıllarda belirmeye başlayan zum, hızla yaygınlaşarak gittikçe daha fazla sayıda filmde ve yoğun olarak yer almıştır. Bu yazıda, bir biçem aracı olarak zumun söz konusu yıllarda Yeşilçam filmlerindeki işlev ve özellikleri ile film dilinde yarattığı etki incelenmiş̧ir. Zumun söz konusu filmlerde kullanımının mizansende önemli bir etki yarattığı görülmüştür. Bu etki zum içermeyen filmlerdeki mizansen özellikleri ile karşılaştırılarak film estetiğindeki değişim tartışıımıştır. Yazıda, ayrıca zum merceğin gelişimi ile zum hareketinin sinemaya girişi ele alınmış; hareketin özü ve kullanımına dair günümüze değin yapılan eleştirel ve kuramsal tartışmalara değinilmiştir.
\end{abstract}

Anahtar Kelimeler: biçem, mizansen, sinema, Türk Sineması, zum

\section{From Dynamic Mise-en-sceneto The Restless Camera: The Zoom in Yeșilçam}

\begin{abstract}
Although the zoom was emerged at the first half of the twentieth century, it has gain edits development and popularity in the post World War II era with the effect of television broadcasting. The zoom shot usage has gained an approval in film making too. The zoom especially has been preffered by the independent film makers since the1950s and 1960s. The role of the zoom has been subject to discussions as aesthetically and practically. The zoom emerged in Turkish cinema in the1960s and its usage has increased rapidly. In this article, beside the functions and the characteristics, influence of the zoom on the film language of Yeşilçam period are investigated. It is concluded that the zoom has an impact on the mise-en-scene of these films. Observed transformation of the film aesthetics has been discussed through the comparison of this impact with the mise-en-scene traits of the films which do not contain the zoom. In the study, it also has been given a brief history of the development of the zoom lens and the usage of the zoom in cinema, and an account of critical discussions on the subject so far.
\end{abstract}

Keywords: cinema, mise-en-scene, style, Turkish Cinema, zoom

1 Yrd. Doç.Dr., Yaşar Üniversitesi 


\section{Giriș}

$\mathrm{S}$ cottie (James Stewart), çatının kenarındaki oluğa tutunmuş sallanırken aşağıya bakar. Seyirci, onun gözünden sokağı kuşbakışı görür. Çerçeve sabittir ancak sokak ve etrafını çevreleyen binalarda sıra dışı bir hareketlilik hissedilir. Ölümle yaşam arasındaki o ince çizgide, düştüğü dehşeti yansıtırcasına, zemin Scottie' den hızla uzaklaşırken üst üste dizilmiş pencerelerin arası garip bir biçimde açılır. Der letzte Mann (Son Adam, F.W. Murnau, 1924)'daki sarhoş kapıcının etrafında dönen dünyayı gösteren türden izlenimci bir bakış açısını yansıtan çekim, o zaman için yeni sayılabilecek bir tekniğin yine Murnau' nun kaydırması ile birleşmesinden oluşmaktadır. Vertigo (Ölüm Korkusu, Alfred Hitchcock, 1959)'nun açılışındaki bu kısa anda olan biten, ileriye doğru yapılan bir kaydırma hareketine karşıık, aynı anda ters yönde yapılan geriye zum (optik kaydırma) hareketidir. Hitchcock meşhur çan kulesi sahnelerinde aynı oyuna tekrar başvurur. Bundan böyle bu etki, filmin adıyla, Vertigoefekti olarak anılmaya başlanacaktır. Eskiden beri bilinen ancak o güne değin pek ilgi çekmemiş görünen zum hareketi yaratıcı bir kullanım biçimi daha bulmuştur.

Renkli film ve sinemaskopla aynı dönemlerde ortaya çıkmış, izleyici için ilgi çekici bir teknik yenilik (Hayward, 2000: 475) biçiminde nitelendirilen ve aslen optik bir hareket etkisi olmasına karşın kamera hareketi türleri arasında sayılabilecek zum (zoom / optik kaydırma), sinematografinin ve dolayısı ile mizansenin ve biçemin ${ }^{2}$ (style)araçlarındandır. Brown (2012: 213) zumu odak uzaklığındaki optik bir değişim olarak tanımlar. Vineyard (2010:17) zum hareketinin genel plandan yakın plana kameranın yerini değiştirmeden geçmeyi, yavaş yapıldığında kısıtı mekânlarda kaydırma (dolly / track) hareketinin yerine kullanabilmeyi, hızlı yapıldığında ise dikkat çekmeyi sağladığını belirtir.

Bir zum mercek, odak uzaklığının değişebildiği, dolayısı ile hem geniş, hem normal, hem de dar açılı (telefoto) mercek özelliklerini aynı anda üzerinde taşıyabilen bir mercektir. Böylece, farklı çekimler için gerektiğinde çok sayıda farklı mercek kullanma intiyacını giderir. Sağladığı bu kolaylığın yanında, zum merceğin estetik açıdan sinema ve televizyona getirdiği en önemli yenilik, odak uzaklı̆ı̆ın çekim anında değiştirilmesiyle ortaya çıkan görsel etkidir. Bu, sinema ve televizyonda yeni bir tür sanal hareket etkisini görüntü diline kazandırır ki, buna zum hareketi denir. Bu hareket, görüntünün yakınlaşması veya uzaklaşmasına göre ileriye(zoom in) ya da geriye zum (zoom out) olarak adlandırıır. Zum hareketi sırasında çekim ölçeği kadar görüntüdeki mekân da bir değişim geçirir. Hareketin ileriye ya da geriye yapılmasına göre, mekânda derinlemesine uzanan nesnelerin arasındaki mesafe uzar ya da kısalır, diğer bir deyişle mizansenin ön, orta ve arka planı birbirinden uzaklaşır ya da sıkışır görünür. Zum üçüncü boyutu sönümlendirir ya da güçlendirir.

Film estetiğinin bir tarihi vardır ve bu tarihi çözümlemek sinemayı anlamak açısından kaçınılmaz bir biçimde önemlidir (Bordwell, 1997: 4). Bonitzer(2011: 22)'in de belirttiği gibi "sinema tarihindeki her yenilik, önce plan denen şu ele avuca sığmaz varlığın daha önce görülmemiş bir kullanımı, hatta nitelik değiştirmesi olarak başlamıştır". Zum mercek ve bu mercekle yapılan optik bir hareket olarak zum, film estetiğine önemli bir yenilik getirmiştir. Zumun yaygın kullanımı filmlerin biçemini büyük ölçüde değiştirmiştir. Bu nedenle, sinemanın biçeme dair tarihi yazılırken filmlerde sahneleme, çekim ölçeği, çekim süresi, kamera hareketi ve açısı, kurgu gibi öğelerin yanında zum ve oynadığı rolün incelenmesi de önem taşır. 
Anlatım araçları bir sanat dalını kendisi kılan özelliklerden biridir. Sinema da kendine özgü anlatım araçlarına sahiptir. Klasik anlatı sinemasında öykünün oynadığı baskın role karşın film, biçem aracılığıyla hayat bulur ve onsuz var olamaz. Anlatı sinemasında anlatı yapısı ve biçem arasındaki ilişki karşılıkı bir ilişki olup biçem de anlatıya ve dolayısı ile anlamın üretilmesine hizmet etmek durumundadır. Sinemada biçemi oluşturan öğeler mizansen, sinematografi, kurgu ve sestir. Mizansen ve sinematografi, diğer bir deyişle sahneleme ve görüntüleme genellikle bir arada ele alınarak filmlerde bu öğeleri inceleyen çalışmalar da sıklıkla mizansen çözümlemesi olarak nitelendirilirler.

Biçemin bir öğesi olarak zum hareketi Türkiye'de olduğu kadar, Amerikan sinema ve televizyon araştırmalarında da yeterince incelenmemiş bir konudur (Hall, 2013: 277).Önce Batı televizyon ve sinemasında kullanılmaya başlanan zum, Türkiye'de de kullanım alanı bulmuş ve bir dönem yaygınlaşarak film estetiğini dikkat çekici bir biçimde etkilemiştir.

Bu çalışmanın amacı, sinematografik bir öğe olarak zumun Yeşilçam Sineması'nda ortaya çıkış ve yaygınlaşma sürecini tespit etmek, niteliğini, işlevini ve mizansen üzerinden film dilini dönüştürücü etkisini tartışarak sinemanın estetik tarihine katkıda bulunmaktır. Yazıda öncelikle zum merceğin tarihsel gelişimi ve estetik özellikleri açıklanmış; zum üzerine yapılan eleştirel ve teorik tartışmalara değinilmiştir. Ardından Türk Sineması'nda ele alınan dönemde zum kullanımı, zumun estetik nitelikleri ve anlatıya katkısı bağlamında işlevleri tartışılarak biçemdeki değişim tartışılmıştır.

İncelemeye konu olan filmler Türk sinemasında Yeşilçam olarak adlandırılan dönemde,1960'lı ve 1970'li yıllarda, zum hareketinin filmlerimize yeni yeni girmeye başladığı ve film yapım sayısının sıçrama yaptığı bir dönemde çevrilmiş 54 filmden oluşmaktadır. Ulaşılabilen filmler arasından her bir yıla ait altı-dokuz arası film rastgele seçilmiştir. Çözümlemede filmlerin videokaset kopyaları ya da internette dolaşımda olan video kopyaları kullanılmıştır. ${ }^{3}$ Bir çekimin zum çekim kabul edilebilmesi için tek bir zum hareketi içermesi burada yeterli görülmüştür. Bazı filmlerde çok sayıda çekimin kademeli olarak ileri ya da geriye art arda zumlar içerdiği de göz önünde tutulursa, toplamda zum hareketi sayısının burada belirtilenlerden daha fazla olduğu ayrıca not edilmelidir. Bunun yanında, herhangi bir çekim ölçeği değişimine yol açmayan, örneğin, oyuncu ve nesne hareketine bağlı kompozisyon değişimlerinde çerçevelemeyi düzeltmek amaçlı yapıldığı anlaşılan kısa zumlar da kapsam dışı bırakılmıştır. Ayrıca, olay örgüsünün bir parçası olmayan nitelikteki başlangıç yazıları da incelemeye dâhil edilmemiştir. Ancak bazen filmin (Örn. Kucaktan Kucağa, Ü. Erakalın, 1966) olay örgüsü kredilerle birlikte başladığından, yani yazılar çekimlerin üzerine bindirildiğinden, buralarda karşılaşılan zum hareketleri veri olarak kabul edilmiştir.

\section{Zum Mercek ve Zum Hareketi}

Zum, yani değişken odaklı merceğin öncüllerinin ortaya çıkışı 19. Yüzyılın ilk yarısına dayanır. Bu yüzyılda genellikle teleskoplar üzerinde çalışılan ve geliştirilen buluş, 20. Yüzyılda film kameralarında kullanılmak üzere gelişim ve kullanım alanı bulmuştur. 1920'lerde Joseph B. Walker, 1930'larda İngiliz Taylor \&Hobson şirketi ile Alman HelmutNaumann, 1940'larda ve 50’lerde Frank G. Back ve 1960'larda Pierre Angénieux modern zum merceği geliştiren isimler olarak bilinmektedirler (Hall,t.y.;Kingslake, 1989:156). Zum merceğin gelişiminin ardında yatan en

3 Sinema araştırmalarında filmlerin yapım yılı ve künye bilgileri gibi çok temel görünen konularda dahi zaman zaman doğru bilgiye ulaşma güçlüğü bilinen bir sorundur. Bu nedenle filmlerin yapım yılı belirtilirken tutarlılık için bu alanda yeni ve kapsamlı bir çalışmanın sonucu olarak ortaya çıkan TSA (Türk Sineması Araştırmaları) veri tabanı esas alınmıştır. Veri tabanına www.tsa.org.tradresinden ulaşılabilir. 
önemli etkenler savaş ve televizyon teknolojisi olmuştur. 1939'da Avusturya'dan Amerika'ya kaçan Back, aslen askeri amaçlariçin zum mercekler tasarlayan bir mühendistir. Televizyon yayıncılığı, zum merceğin gelişiminde rol oynayan ikinci önemli alanı oluşturmuştur (Hall, 2012; Kingslake, 1960). Zum mercek, sinemadakinin aksine, başlangıçta henüz video kayıt teknolojisinin olmayıp yayınların anında iletildıği, o an cereyan eden olayları aktarmak için çekimi durdurup farkı odak uzaklıklı mercekleri değiştirerek konuya yaklaşıp uzaklaşmanın mümkün görünmediği televizyon yayıncılığında önemli bir kolaylık sağlamış görünmektedir.

Frank G. Back, 1947'de yayınlanan tanıtıcı yazısında, geliştirdiği “Zoomar" merceği "değişken odak uzaklıklı bir mercek" olarak adlandırır ve tasarım amacını ve işlevini şu şekilde belirtir: "Zoomar değişken odaklı (varifocal) mercek, kameranın mevcut yöntemlerle objeye yaklaşıp ondan uzaklaşmasının imkânsız olduğu ya da ekonomik olmadığı durumlarda zum çekimi yapmaya yarayan bir araç olarak üretildi. Perdede kamera nesneye doğru yaklaşıyormuş gibi görünse de gerçekte kamera -ve nesne- sabit kalır. Mevcut hareket optik olarak üretilir"(57, 58).Yazıda ayrıca merceğin, eğitsel ve belgesel filmlerde harita, resim ve maketlerin görüntülenmesinde; topla oynanan oyunlar ve otomobil yarışları gibi spor etkinliklerinde; sanayi, ticaret ve tıp alanlarında sağladığı yakın çekimlerle son derece yararlı olabileceği örneklendirilerek vurgulanır. Back yazısını şu cümlelerle bitirir: "Şunu söylersek hiç de abartılı olmaz: Yakın çekim, yani D. W. Griffith tarafından sinemaya armağan edilen bu güçlü ifade aracı, zum merceğin gelişiyle gerçek anlamını buldu. Zumar mercek, şu ana kadar bu tekniğin kullanımını karmaşık hale getiren güçlükleri ortadan kaldırıyor"(63).

Back ve arkadaşları, merceği başlangıçta $16 \mathrm{~mm}$. ve $35 \mathrm{~mm}$. film kamerası için geliştirmiş olmakla birlikte, televizyon yayıncılığında gelecek vadettiğini görerek elektronik kameralarla uyumlu bir çeşidini tasarlayıp üretmişler (Back ve Herbert, 1955), Amerika'da sayıları hızla artmakta olan televizyon kanallarına pazarlamışlardır (Hall, 2013: 280; Kingslake, 1989: 156). Paramount Newsreel, Back'in Zumar merceğini edinen ilk büyük şirket olur. Gerek Back'in Zoomar'ı gerekse 1950'de çıkan Pan-Cinor yalnızca 20- 60 mm arası değişebilen odak uzaklıklı, son derece kısıtlı zum hareketi sağlayan merceklerdir. Bu konudaki asıl gelişme 1950'lerden itibaren gerçekleşmiştir (Salt, 1977:48).

Joseph B. Walker, önceki yıllarda icat ettiği merceği geliştirerek 1950'lerdeElectra-Zoom adıyla üretir. Modern zum merceklerdeki en önemli gelişmeyi ise yüksek optik kalitesi ve on kez yakınlaştırabilme kapasitesiyle 1960'larda Pierre Angenieux yapar. 1960'lar ve 1970'lerde Avrupa ve Amerikan sinemasındaki en sıradışı zum efektleri Angenieux'nun $12-120 \mathrm{~mm}$ ve $25-250$ $\mathrm{mm}$ mercekleri ile hayat bulur (Hall,t.y.).

Araştırmalar, zum merceğin öncellikle aksiyona daha da yaklaşmak ve izleyicide heyecan uyandırmak amacıyla geliştirilmiş bir araç olarak ortaya çıktığını belirtmekte. Mercek, başta özellikle dönemin en popüler oyunu olan Baseball maçlarını görüntülemek için kullanılmış ve merceği kullanan kanallar, izleyicilerine oyuncuların daha büyük ve canlı görüntülerini sunduklarını tanıtımlarında sıkça vurgulamışlardır. Zum merceğin Amerika'daki kullanımı takip eden yıllarda diğer sporların görüntülenmesinde ve haber programlarında da yaygınlaşır. 1950'lerin ortasında televizyon yayıncılığında yaygın bir araç haline gelir. Stüdyo ve dış çekim canlı yayınlarında sağladığı kolaylığın yanında dönemin Amerikan televizyon dramalarında da zum çekimi kullanım alanı bulmuştur (Hall, 2013: 280-283).

Zum mercek ve zum hareketinin sinemadaki kullanımı sesli dönemin başlarına kadar uzanmakta ise de uzunca bir dönem sınırlı kalmıştır. 1930'lardaLove me Tonight (Rouben Mamoulian, 1932), 
American Madness (Frank Capra, 1932), The Four Feathers (Namusum İçin, Cooper vd. 1929), Dirigible (Frank Capra, 1931), One Way Passage (Tay Garnett, 1932) ve Edge of Darkness (Narvik Baskını, Lewis Milestone, 1942) zum hareketinin sinemada yer aldığı ilk filmlerden bazıları olarak sayılabilir. Salt (1992:244), zumun Amerika'da daha çok televizyonda kullanıldığını ancak Apache (Asi Cengaver, Robert Aldrich, 1954) ve The Incredible Shrinking Man (Kendi Kendine Küçülen Adam, Jack Arnold, 1957) filmlerinde sınırlı sayıda da olsa yer aldığını yazar. 1950'lerin sonlarından itibaren sinemada zum hareketine daha sık rastlanmaya başlanır (Hall, 2012:227).

Sinemacıların 1950'ler ve 1960'larda stüdyoların dışına çıkarak daha fazla dış çekim yaptıkları yapımlarda; uzak mesafelerde, basit aydınlatma ve sahneleme koşullarında zum mercek önemli bir pratik araç olur ve özellikle genç sinemacılar tarafından rağbet görür (Bordwell 1997:247). Avrupa'da başta Das Madchen Rosemarie (Rolf Thiele, 1958)' nin çok sayıda zum hareketi içerdiği; zumun dönemin başkaca Alman filmlerinde de yer aldığı, ancak en dikkat çekici erken kullanımının Roberto Rossellini'nin Era Notte a Roma (Roma'da Karartma, 1960) ve Vival'Italia! (Garibaldi, 1961) filmlerinde olduğu ve Rossellini'nin bu deneyden sonra zumdan uzaklaştığı (Salt 1992: 244) belirtilir. Sarrisise (akt.Belton, 1980:22), Rosselini'nin zumu ilk defa India: Matri Bhumi (1959) filminde kullandığını söyler. Ayrıca, Fransız sinemacı Claude Chabrol, La Femme in-fidele(Vefasız Kadın,1968), Que la betemeure (1969) ve Le Boucher (Kasap, 1969) filmlerinde duygusal bir etki için zumu çarpıcı bir biçimde kullanır (Belton, 1980: 26).

Avrupalı bağımsız filmler kadar Hollywood yapımlarında da zum $60^{\prime}$ 'ı ve $70^{\prime}$ li yıllarda sıkça yer alır. Mercek ve yarattığı etki bir dönem Amerikan sinemasını da estetik açıdan önemli ölçüde etkilemiştir. 1960'larda Sam Peckinpahzum çekimi film biçeminde çokça tercih etmiştir. Takip eden yıllarda Yeni Hollywood sineması adı verilen önemli sayıda bağımsız ve küçük bütçeli Amerikan filminde zumun yaygınlaştığı görülmüştür. Diğer yanda Uzakdoğu dövüş filmlerinde de dövüş sahnelerini yoğunlaştırmak için kullanılmıştır (Belton, 1980; Bordwell, 1997; O’Brien, 2012).

Bordwell(1997: 249), çok sayıda yönetmenin sahneleri çevrinme ve zum içeren uzun çekimlerle doldurarak dramatik anlar için daha sertzumlar kullandıklarını,-Berny Levy'den ödünç aldığı terimle- "arama ve açığa çıkarma" nın, yani sahnede olan biteni tarayan ve önemli detayları seçen tavrın1960'ların ve 70'lerin belirgin bir özelliği haline geldiğini belirtmekte. Bu tarzın Alexander Petrovic ve Robert Altman gibi yeni yönetmenler kadar Visconti, Fellini, Bergman ve Rossellini gibi eski ustalar tarafından da uygulandığını not düşmektedir. Ayrıca, çevrinme ve zum yaklaşımının bazen düşük bütçeli yapımla özdeşleştirilse de bazı çok yeni sahneleme fırsatları sunmuş olduğunu söylemektedir(1997: 250).

Belton(1980:25) ise televizyon yayıncılığının etkisine dikkat çekerek zumun sinemada yayılmasının Robert Altman, Blake Edwards, John Frankenheimer, Andrew McLaglen, Robert Mulligan ve Sydney Pollack'ın New York'un televizyon dünyasından Hollywood'a geçerken zumu da beraberinde getiren yönetmenlerden bir kısmı olduğuna işaret etmekte. Ayrıca Altman(McCabe ve Mrs. Miller, 1971) ve Mulligan (Summer of '42, 1971)'ı zumun "belki de en parlak uygulayıcıları" olarak nitelendirmektedir.

Deneysel sinema kanadında ise Michael Snow'un Wavelength (1967) ve ErnieGehr'in Serene Velocity (1970) filmleri, zum merceğin farklı odak uzaklıkları konumunda kullanılarak yapılan çekimlerin art arda eklenmesiyle yakınlık-uzaklık ve perspektif değişimi ilişkilerini çarpıcı bir biçimde sergileyen çalışmalardır (Wees, 1992:51-52).

Zum hareketinin film biçemindeki yerini tanımlayan ve tartışan sınırlı sayıda çalışma mevcuttur. 
Zum üzerine başlangıçta yazılanlar daha çok teknik bir yenilik olarak zum mercek üzerinden hareketi tanımlayan ve yararlarını açıklamaya çalışan niteliktedir. Zum merceklerin tanıtımlarında ya da kameraman ve teknisyenlerin yazdıklarında bu merceğin kameranın konumlandırımasına olanak sağladığı kadar, sınırlı set olanakları içinde bazı durumlarda kaydırma hareketini ortadan kaldırmaya olanak tanıdığı vurgulanmaktadır (Hall, 2012:225, 226). Örneğin, American Cinematographer'daki bir yazıda, uzun bir çekimde kameranın gidebildiği yere kadar ileri doğru kaydırma (dolly /track) hareketi yapabileceği, bir nesne tarafından engellenmesi halinde zum ile oyuncunun yüzüne kadar yakınlaşmaya kesintisiz devam edebileceği belirtilmekte (akt. Hall, 2012:229).Türkiye'den verilebilecek bir örnekte de Nijat Özön (1963: 87), zumu optik kaydırma olarak Türkçeleştirmiş ve "değişir odaklı mercekle elde edilen kaydırma" olarak tanımlamıştır. Zum ve kaydırma benzerliklerinden ötürü sinemada kaçınılmaz olarak sıkça beraber ele alınan iki kavramdır. Buna karşın kaydırma ve zum hareketinin biçemde yarattı̆ı̆ı etkide temelde bazı farklar vardır: İleri veya geri kaydırma hareketinde kameranın mekândaki konumunun değişmesinden dolayı çerçevedeki perspektif de değişirken zum hareketinde perspektif değişmez. Zum çekimde çerçevelenen nesnelerin büyümesi ya da küçülmesi yapay bir etki uyandırır ve merceğin niteliğinden ötürü net alan derinliği değişir. Kaydırmada ise, insan gözü gibi davranan kameranın mekândaki ileri / geri hareketi sonucu deneyimlediği (gördüğü)perspektif değişimi, perdedeki görüntünün arka planına bir hareketlilik olarak yansır ve ayrıca merceğin odak uzaklığı sabit kaldığı için net alan derinliği de etkilenmez.

Örneklerden de anlaşılacağı üzere zum hareketine, kısaca kameraya esneklik kazandırmak, mekân sorunlarını aşmak ve kaydırmanın yerini alabilecek bir hareket olarak kullanım amacı biçilmekte; ancak bunlardan biri öne çıkmış görünmektedir. Belton (1980:21), 1930'lardan 1970'lere kadar zum hakkında yazılanların çoğunun zumu kamera hareketine bir yenilik, bir katkıdan çok, kaydırmaya bir ikame olarak gördüğü eleştirisini getirmektedir. Aynı makalede Belton (1980: 27), Yeni Dalga'dan beri zumun sinema dilinin evriminde önemli bir rolü olduğunu; özellikle mekânı bozuma uğratması ve kendi öz farkındalığıyla İkinci Dünya Savaşı öncesi geliştirilmiş olan bütün kodları parçaladığını vurgulamaktadır. Bunu bir olumsuzluk olarak değil, yeni ve yaratıcı bir gelişme olarak gördüğü anlaşılmaktadır. Kaminsky (akt. Belton, 1980:21) de zumun geleneksel kaydırma hareketine ikame kabul edilmesi düşüncesine karşı çıkarak onun aslen farklı türde bir hareket olduğunu iddia edenlerden biridir.

Andrew Sarris (akt.Belton, 1980: 22), Rossellini'nin zumlarının fikirler ve kavramlar ifade etmek gibi soyut düzeyde -kamera hareketinin fiziksel katılığıyla sağlanamayacak- bir anlatım kazandırdığını belirtir. Her bir görüntünün akışkan bir şekilde, kesintiye uğramadan birbirine dönüştüğünü, birey-çevre, yakın-uzak, parça-bütün ve perspektif ilişkisinin bu mercekle dinamik, akışkan, mekânda devinen bir nitelik kazandığını savunur.

Sobchack (1990: 25) ise, makalesinde zum ve kaydırma hareketlerini karşılaştırarak ileriye zumun izleyici açısından nesneye doğru izlenimsel düzeyde diğer bir deyişle daha içsel ve zihinsel bir yakınlaşmayı temsil ederken, kaydırma hareketinin ise zihinsel olduğu kadar bir jest gibi fiziksel bir yakınlaşma taşımasıyla dışa vurumsal bir nitelik taşıdığını belirtir.

O’Brien (2012) da Bordwell gibi, zumun psikolojik bir etki yaratan, kolaylık sağlayan ya da kaydırma hareketine ikame bir araç olarak ele alınmasının dışına çıkarak bir başka duruma işaret eder. Zumun yayılma sebebi olarak 1960'larda ve 1970'lerde özellikle küçük yapımların stüdyo dışına çıkıp dış çekim ağırııkı film yaptığı Yeni Hollywood sinemasını etken gösterir. O'Brien (2012), fiziksel çekim koşullarının etkisini vurgulayarak zum mercek ve zum hareketinin kullanımının biçeme dair bir tercihten öte yapım koşularının bir zorlaması olarak estetiği biçimlendirdiğini öne 
sürerek dikkati metin dışı bir alana çekmektedir. Zira, Gibbs (2011) de mizansenin oluşmasında yapım süreçlerinin ve buralarda alınan kararların da son derece etkili olabileceğini; bu nedenle, mizansen çözümlemesinde çerçeve içi kadar dışının da dikkate alınabileceğini göstermiştir.

Zumun Doğu sinemasındaki kültürel kaynakları üzerine fikir yürüten bir çalışmada ise Paul Willemen (2013: 108),zumu geleneksel kültürlerdeki anlatıcı merkezli performansın; bizdeki haliyle örneğin meddahlık olarak adlandırılabilecek bir halk anlatıcılığının modernleşmiş, sanayileșmiş bir versiyonunun (sinema ve elektronik görüntü) aracı olarak görür ${ }^{4}$. Batı sinemasındaki anlatıcının özdeşleşmeyi hedefleyerek kendisini sürekli gizlemeye çalıştığı yaklaşıma aykırı olarak; doğulu anlatıcının kendi varlığını sık sık hatırlatan bir jest, retorik bir beceri olarak nitelendirir zum kullanımını. Argümanını dinleyici kültürde -burada sözlü (oral) yerine Godzich (1994)'ten ödünç aldığı işitmeli (auditive) kültür terimini kullanıyor - "ağzı açık bırakma"nın yani duygulara hitap etmenin önemli olduğu tespitiyle destekler(Willemen 2013:106,107).

\section{Yeșilçam'da Zum}

$\mathrm{Bu}$ çalışma zum hareketinin Türk Sineması'na ilk girişinin kesin bir tarihini sunmamakla birlikte, hangi yıllarda kullanılmaya başlandığı ve yaygınlaşma süreci hakkında bazı tespitlerde bulunmakta; biçeme dair bir araç olarak Yeşilçam filmlerindeki niteliği ve işlevi üzerinden film estetiğindeki dönüştürücü etkisini tartışmaktadır.

Araştırmamızda ele alınan yıllarda ${ }^{5}$ yapılmış filmler arasından rastgele seçilerek incelenen örneklerde zum çekimin gittikçe daha fazla tercih edilir bir araç olduğu ortaya çıkmaktadır. Bu, gözlenebilen bir olgudur ve zum içeren çekimler sayıldığında ortaya şu tablo çıkmaktadır:

Örneklemdeki 1964 yılının altı filminde de herhangi bir zum hareketinin varlığına rastlanmazken; 1965'te bir; 1966'da üç; 1967'de bir; 1968'de iki; 1969'da beş; 1970'de beş ve 1971'de yedi filmde zum kullanıldığı görülmektedir (Tablo 1). 1965-1968 yılları arasındaki filmlerde daha sınırlı sayıda kullanılan zum, 1969 yılından itibaren daha sık kullanılmaya başlanmış ve 1971'de ciddi sayılara ulaşmıştır. Diğer bir deyişle, zum hareketinin kullanımının yönetmen ve kameramanlar arasında yıldan yıla yayılmasının yanında, her bir film içindeki kullanım sıklığı da belirgin bir biçimde artmıştır. Zum, bazı filmlerde daha sınırlı tutulup, hatta hiç kullanılmazken bazı filmlerde yüz ve daha üzeri sayıdaki çekimde zum hareketine rastlanmaktadır. Böylece, 1964 yılından örnek alınan filmlerde herhangi bir zum hareketi içeren çekim yok iken; 1971 yılı filmlerinde bu sayı toplamda 680'e ulaşmıştır (Grafik 1). Bu durum, anlaşılacağı üzere, söz konusu filmlerin estetiğinde çarpıcı bir etki oluşturmaktadır. Burada hatırlatılması gereken bir nokta da tabloda zum hareketi içeren çekim sayısının verilmiş olduğu dikkate alındığında; tek bir çekim içinde birbiri ardına gelen zumlarla birlikte zum hareketi sayısının gerçekte daha fazla olduğudur. Zumun Yeşilçam filmlerinde çeşitli işlevleri vardır. Zum mercek ve bir biçem öğesi olarak zum hareketi, bu filmlerin dili üzerinde tahmin edilenin de üzerinde bir etkiye sahip olabilir.

4 Nitekim N. Erdoğan da Willemen'e benzer şekilde Yeşilçam'daki bu çeşit yabancılaştırıcı sinemasal araçları Brechtyen bir estetik yerine Karagöz, Meddah, Ortaoyunu geleneksel kültür öğeleri ile ilintilendirir. Bkz. "Yeşilçam'da Sessiz Bedenler, Bedensiz Sesler",http://neziherdogan.net/articles/filmsoundtr/bedenses.htm

5 İncelenen filmler 1964-1971 yılları arasındandır. Bu,aynı zamanda enflasyonist olarak tabir edilen dönemin ivmelendiği yıllardır. Yapım sayısındaki ciddi artış1961'den itibaren görülmekle birlikte 1964'te film sayısı bir sıçramayla 125’ten178'e çıkmıştır ve 1968 yılı haricinde (177) film yapım sayısı aşağıya düşmemiş, yıldan yıla artmıştır. 
Tablo 1: Filmler ve Zum Çekim Sayıları

Filmin Adı

Tığ Gibi Delikanlı

Gençlik Rüzgarı

Evcilik Oyunu

Keșanlı Ali Destanı

Ağaçlar Ayakta Ölür

Atçalı Kel Mehmet

Garip Bir Izdivaç

Sevmek Zamanı

Son Kușlar

Tehlikeli Adımlar

Veda Busesi

Zennube

Ah Güzel İstanbul

Erkek ve Diși

Gariban

İntikam Uğruna

Karakolda Ayna Var

Kucaktan Kucağa

Meleklerin Intikamı

Namusum İçin

Siyah Otomobil

Bir Dağ Masalı

Merhamet

Sefiller

Ölüm Saati

Üç Sevdalı KIz

Yağmur Çiselerken

Gül ve Șeker

Sabahsız Geceler

Yalan Yillar

Kezban

Ömrümün Tek Gecesi

Kuyu

Așk Bu değil

Kaldııım Ciçeği

Kınalı Yapıncak

Ölmüș Bir Kadının Mektupları

Sevgili Babam

İneyen Nağmeler

Bütün Așklar Tatlı Bașlar

Kezban Romáda

Ölünceye Kadar

Saadet Güneși

Șoför Nebahat

Umut
Yilı

1964

1964

1964

1964

1964

1964

1965

1965

1965

1965

1965

1965

1966

1966

1966

1966

1966

1966

1966

1966

1966

1967

1967

1967

1967

1967

1967

1968

1968

1968

1968

1968

1968

1969

1969

1969

1969

1969

1969

1970

1970

1970

1970

1970

1970
Yönetmeni

Zum Çekim Sayısı

Ülkü Erakalın

Nejat Saydam 0

Halit Refiğ 0

Atif Yilmaz 0

Memduh Ün $\quad 0$

AsafTengiz 0

Nejat Saydam 0

Metin Erksan 0

Erdoğan Tokatlı

Mehmet Dinler 0

Ülkü Erakalın 23

Türker İnanoğlu

Atıf YIlmaz 13

Halit Refiğ 0

Aram Gülyüz 0

Türker İnanoğlu

Halit Refiğ 13

Ülkü Erakalın 0

Osman Seden 0

Memduh Ün 0

Aram Gülyüz 22

Turgut Demirağ 56

Osman Seden 0

Zafer Davutoğlu 0

Ertem Görec 0

Sırrı Gültekin 0

0 . Nuri Ergün 0

Osman Seden 0

Ertem Göreç 0

Nejat Saydam 0

Orhan Aksoy 10

0 . Nuri Ergün 24

Metin Erksan 0

0 . Nuri Ergün 3

0. Nuri ErgünO

Orhan Aksoy 13

Ülkü Erakalın 69

Aram Gülyüz $\quad 81$

Safa Önal $\quad 60$

Aram Gülyüz 0

Orhan Aksoy 5

Safa Önal 62

Nejat Saydam 0

Süreyya Duru $\quad 69$

Yılmaz Güney 20 


$\begin{array}{llll}\text { Yavrum } & 1970 & \text { Orhan Aksoy } & 89 \\ \text { Beyoğlu Güzeli } & 1971 & \text { Ertem Eğilmez } & 125 \\ \text { Bir Teselli Ver } & 1971 & \text { Lütfi Ö. Akad } & 10 \\ \text { Feride } & 1971 & \text { Metin Erksan } & 247 \\ \text { Gönül Hırsızı } & 1971 & \text { ArșavirAlyanak } & 14 \\ \text { Hayat Sevince Güzel } & 1971 & \text { Temel Gürsu } & 133 \\ \text { Kader Unuttu Beni (Sabır Duası) } & 1971 & \text { Mehmet Bozkuș } & 13 \\ \text { Öldüren Șehir } & 1971 & \text { Orhan Aykanat } & 0 \\ \text { Son Hıçkirık } & 1971 & \text { Ertem Eğlmez } & 138\end{array}$

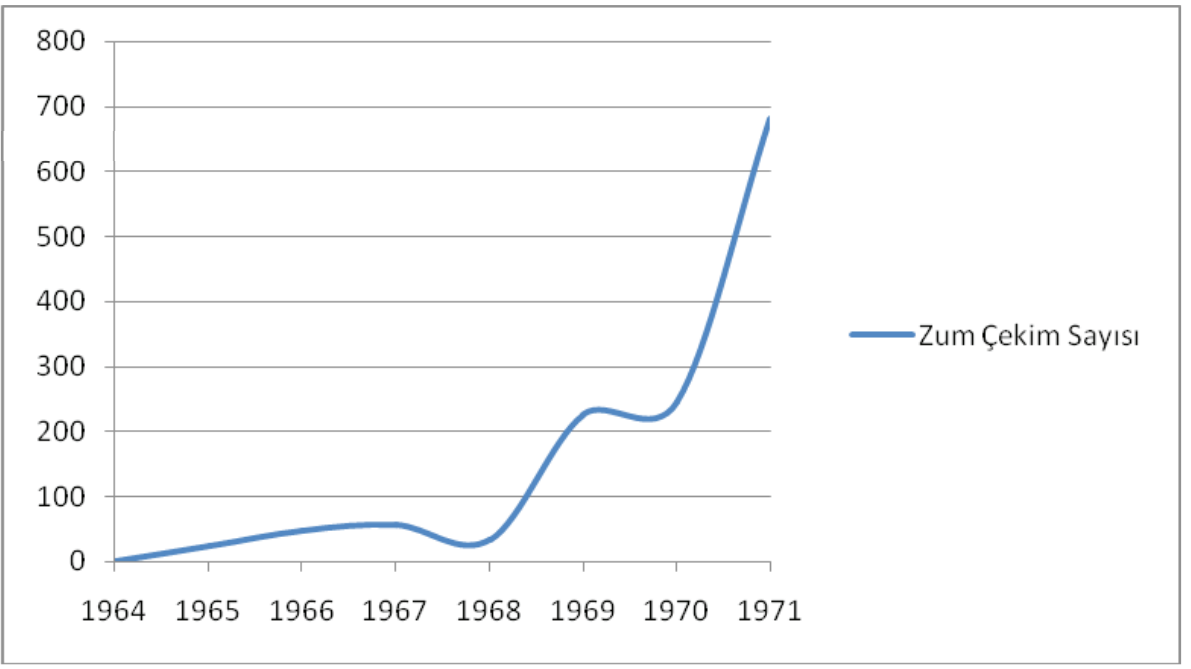

\section{Kesmenin Yerini Alan Zum}

Zum, filmde devamlılık ve kesme ilişkilerini etkileyen bir araçtır. Zumun Yeşilçam filmlerinde gördüğü işlevlerden biri, kesme yapmadan ölçek değiştirme, diğer bir deyişle yeniden çerçeveleme sağlamasıdır. Örneğin, kamerayı durdurup daha yakın bir çekime kesme ile geçmek yerine ileriye zum hareketi ile geçilir. Bunun en aşırı biçimini birbiri ardına kademeli olarak yapılan, eklemlenmiş ya da salınımlı diye nitelendirilebilecek zumlar temsil eder. Metin Erksan'ın Feride (1971)'sinde, Feride (Emel Sayın)'nin İzzet (Reha Yurdakul)'in evinde tuzağa düşürülüş sahnesinin açılışındaki çekimde ileri geri üç zum hareketi vardır. Çekim, İzzet'in yakın çekiminden geriye doğru zumla başlar ve genel çekimde duraklar. Çekim, kapıdan Feride'nin girmesi ile birlikte son noktasında Feride ve İzzet'i çerçeveleyen ileri bir zumla devam eder ve hareket halindeki Feride'nin daha da yakın bir çekimine ulaşan bir başka zum ile sonlanır. Safa Önal'ın yönetmenliğini yaptığı İnleyen Nağmeler (1969) adlı filmde Zeki (Zeki Müren), sevgilisi Jülide (Çolpan İlhan)' ye hastane ziyaretinde evlenme teklif ettiğinde, hızlı bir zum Jülide'nin şaşkın yüzünü yaklaştırır. Ardından, çerçeve Zeki'yi de kapsayacak şekilde geriye zumla genişler ve Zeki'nin Jülide'nin göğsüne kapanmasıyla ikisine doğru yapılan zum ilebiter. Bütün bu olan bitenler sırasında kamera ne bir konum değiştirmiş ne de -çerçeveyi düzeltmek için bir zorunluluktan kaynaklanan hafif bir çevrinme dışında- başka bir hareket yapmıştır. Son Hıçkırık (Ertem Eğilmez, 1971)'ın hemen açılışındaki çekimdekine benzer şekilde Kenan (Metin Serezli)'ın filmin başlarında geçmişi hatırladığı sahne bahçedeki ağacın çiçeklerinden geriye doğru bir zumla açılır ve çekim kesilmeden tam ters yönde bir zumla köşkün penceresini izleyiciye yaklaştııır. Zum kullanımının had safhaya ulaştığı Feride 
(Metin Erksan, 1971)'de filmin doksan dakikalık süresine karşın zum hareketi içeren 247 çekimle dakika başına yaklaşık üç zum çekim düşmektedir. Bu sayıya yukarıda verilen örnekte olduğu gibi aynı çekimde art arda yapılan ikinci ve hatta üçüncü zumlar dâhil değildir. Kısa diyaloglardaki açı-karşı açı çekimleri ya da bazı nesnelerin yakın çekimleri gibi sabit çerçeveler zumların arasına serpiştirilmiş ara çekimler (insert) haline gelmişlerdir. Filmde zum içermeyen bir çekim neredeyse istisnadır. Kaydırma hareketi yok denecek kadar azdır ve mevcut kaydırmaların bittiği noktada bile çekim çoğu kez bir zum ile devam eder. Eğer Erksan, bu filmi bilinçli olarak yaptı ise, Feride tam anlamıyla "yalnızca zumlardan oluşan bir film nasıl olurdu?" sorusuna yanıt arayan deneysel bir çalışma olarak dahi nitelenebilir.

Zumların peş peşe birbirini takip ettiği ve gelgitlere dönüştüğü filmlerden bazıları Son Hıçkırık , Beyoğlu Güzeli (Ertem Eğilmez, 1971), Yavrum (Orhan Aksoy, 1970) ve Sevgili Babam (Aram Gülyüz, 1969)'dır. Zum hareketi içeren çekimler dizisi Beyoğlu Güzeli'nin ilk anından itibaren başlar ve filmin ortalarındaki gazino sahnesinde olduğu gibi bazı sahnelerde gittikçe yoğunlaşır. Zum bu filmlerin dokusuna öylesine nüfuz etmiştir ki hareketsiz olması beklenen kısa çekimlerde dahi çok kısa bir zum hareketi zaman zaman su yüzüne çıkmaktadır. ${ }^{6}$ Anlama yeni bir şey katmadığı halde çoğu kez zuma başvurulur. İnleyen Nağmeler'in ortalarında Zeki Müren dostlarıyla bir akşam yemeğinde ayağa kalkıp şarkı söylemeye başladığında, zum nedeni anlaşılamayan bir ara çekim olarak boş sandalyesini yakınlaştırır. Başka bir sahnede Zeki piyano başında tek başına sevinçle şarkı söylerken ayağa kalkıp kameraya doğru yaklaştığında çekim yüzünü sadece biraz daha yaklaştıran kısacık bir zumla sonlanır. Yavrum'da finale doğru, deniz kıyısında kayalığın üzerinde oturmuş Emine (Semra Sar)'ye üç kısa çekimde yaklaşılan an, kesmenin gücünün hatırlandığı nadir sinemasal anlardandır.

Zumun kesmenin yerini alışı aynı zamanda film yapımında pratiklik sağlamaya da hizmet etmektedir. Sahne çok sayıda çekime bölünmek yerine zum hareketiyle çoğu kez tek bir seferde görüntülenmeye çalışıı. Oysa kesmede ise devamlılık açısından daha genel çekimlerden yakın çekime yapılan kesmelerin uyumlu olması gerekir. Zum böylece nesnenin konumu ya da hareket halinde ise hızı ile bağlantılı olarak devamlılığ uygun kesme yapabilme kaygısını azaltmaya yarar. Bu, hem devamlıı̆g daha az dikkat sarf etmekten dolayı hem de çekimin sık sık bölünmesini önleyerek sette kamera ve oyuncu trafiğini azaltarak zaman kazandırdığı gibi; oluşan sekans çekimler kurgu sürecinde de kolaylık sağlamaktadır.

Zum ayrıca atlamalı kurguda tercih edilen bir geçiş ve de merak uyandırma aracı olarak kullanılır. illeriye doğru bir zum ile biten çekim ve/veya sahnenin ardına geriye zum ile açılan bir çekim ve/veya sahnenin eklenmesi çok sık kullanılan bir yöntemdir. Sahne başlarında çok yakın bir çekimden genel çekime doğru zum ile geçilirken mizansen bir tiyatro perdesinin açıışı gibi ortaya çıkar. Oyuncular ve mekân bir anda değil yavaş yavaş belirirler ve zumun ulaştığı son noktada her şey görünür hale gelir. Böylece genel çekime bir anda yapılan kesme ya da zincirleme ile bir geçiş yerine zum mizansen bilgisini izleyiciye yavaşça aktarır. Çekimin başında çok yakından görülen nesne ya da oyuncunun nerede ve/veya nasıl bir durumda, kimlerle bulunduğu sorusu izleyicinin aklına ilk düşen şeylerden biridir. Bu tarz bir kullanım, daha çok sinema tarihinin

6 Bir fikir vermesi açısından bu örneklerdeki zum sayısı Salt'un verileri ile karşılaştırıldığında, veri tabanında kamera hareketleri sayılmış olan 43 filmden hiç birinde bu sayıda zum hareketi yoktur. En sık zum kullanan filmlerden biri olan ve toplamda 310 kamera hareketi içeren The Blair Witch Project (Daniel Myrick, Eduardo Sanchez, 1999)'te 31 adet zum vardır. Diğer bir deyişle zum, toplam kamera hareketlerinin yalnızca yüzde 10'unu oluşturmaktadır. Bertolucci'nin onlarca kaydırma, çevrinme ve vinç hareketi içeren son derece hareketli kamerasını yansıtan IIConformista (BernardoBertolucci, 1970)'da ise 37 zum vardır. Buna karşın, bu filmlerdeki herhangi bir kamera hareketi içermeyen çekimlerin sayısı her zaman daha fazladır. (Kaynak: www.cinemetrics. Iv) 
erken dönemlerinde yaygın olarak kullanılan bir geçiş ve efekt olan irisi hatırlatır. Bu geçiş türü, çekim ölçeği kavramı ve kullanımının henüz kısıtlı olduğu bir dönemde, kesmeye (kurguya) başvurmadan görüntünün değişmesini de sağlamaktaydı.

Bu dönemde yeni yeni belirmeye başlayan renkli filmin çok masraflı olduğu, film maliyetlerini yükselterek küçük şirketlerin ortadan kalkmasına sebep olduğu (Kırel, 2005: 207-215) göz önünde bulundurulursa zumun sıklaşmasında artan maliyetlerin önemli bir etken olduğu düşünülebilir. Nitekim, burada ele alınan ve zuma çok sık başvuran filmlerin hemen hepsi renkli çekilmiştir.1967'de çevrilen çok az sayıdaki renkli filmden biri olan Bir Dağ Masalı'nın yoğun zum kullanımıyla diğer filmlerden farklılaşması da bu düşünceyi desteklemektedir. Üstelik bu yıllar maliyetlerle ters orantılı bir şekilde sinemamızda yapım sayısının hızla artığı bir döneme denk gelir. Senaryolardaki, temalardaki basitlik ve tekrar bir yana, biçem açısından da zumun, az zamanda çabucak film üretme zorunluluğu altında üzerine düşen rolü oynamış olduğu söylenebilir.

\section{Çı̆̆lık Etkisi}

Zumun Yeşilçam filmlerindeki en önemli işlevlerinden biri vurgulama ya da imlemedir. Zum, sıkça, sesin yükselmesinin ya da patlamasının görsel bir eşdeğeri olarak hizmet görür. Aslen ses ve görüntü karakter olarak birçok farklılık içerir. Sesin patlama anındaki dalgalanması görüntüde birebir mümkün olmasa da- ancak böyle var olabilmektedir. Bu, genellikle ani zum hareketlerine eşlik eden sesin varlığından da anlaşılabilir. Ölünceye Kadar (Safa Önal, 1970)'ın finalindeki mahkeme sahnesinde Nejat (Ayhan Işık) bağııı "Yalan!" (geriye zum). Aynı filmde Nejat'ın savcı arkadaşının Nesrin (Zuhal Aktan)'e "Asacaklar Nejat'ı" dediği an çığlık atan Nesrin'in yüzüne doğru ileri zum yapılmakta ancak bu sefer zum hareketine yüksek perdeden bir müzik eşlik etmektedir. Siyah Otomobil (Aram Gülyüz, 1966)'de otomobilin çocuğa çarpma anında çığlık atan çocuğun yüzüne doğru çok hızlı bir zumla yaklaşılır. Fikret (Hülya Koçyiğit), kocasının verdiği haberde Nejat (Ediz Hun)'ın adını duyduğunda o ana kadar durağan olan çekimde izleyiciyi birdenbire kadının şoke olmuş yüz ifadesine yaklaştıran ileriye zumla beraber dramatik bir müzik yükselir.

Ancak bazen, sessizlik anlarında bile zum tek başına da görsel bir patlama, bir çığlık etkisi gösterir. Yavrum'da dedesi (Münir Özkul)'nin ölüm haberini aldığında Ayşe (Zeynep Değirmencioğlu)'nin yüzünü yakınlaştıran ama ne bir çığlık ne de benzeri bir müziğin eşlik ettiği andaki zum ile Ayşe'nin gösterilen bir resimden annesinin kimliğini öğrendiği, yani o ana kadar aslında izleyicinin bildiği bir gerçeği karakterin keşfetmesi anında kullanılmış olan zum iyi birer örnektir.

Zum bu yönüyle sesle karşılaştırıldığında hem benzer hem de zıt bir karaktere sahiptir. Ses seviyesinin (volume / hacim) aniden artması mekânda kapladığı alanın artmasına işaret ederken, zumda ise en çarpıcı patlamalar - tam tersine- mekânın küçüldüğü, derinliğin sönümlendiği, nesnenin kendi üstüne kapandığı ama perdede/ekranda birden büyüyerek hacim kazandığı ileriye zum anlarında karşılığını bulur. Zum hızının artması, diğer bir deyişle süresinin kısalması da bu etkiyi güçlendirir. Böylece zum ne kadar çabuk ise görsel patlama da o derece büyük olur; o derece şiddetli bir sesin karşılığı olur.

\section{Hareket Etkisi}

Zum, pek çok kez hareket katma, dinamizm sağlama amacına da hizmet eder. Kurgunun, oyuncu/ nesne ve kamera hareketinin sınırlılığından ya da tamamen yokluğundan kaynaklanan durağanlığı örter. Uzun ya da durağan çekimlere hareket katmasının yanı sıra, danslı, dövüşlü sahnelerde kurgunun yaratamadığı ritim zum aracılığıyla üretilir. Kurgunun bu konuda oynadığı rolün önemi, 
başta Eisenstein olmak üzere, Sovyet Montaj sinemacılarından beri bilinen bir olgudur. Mascelli (1998: 162) de pek çok kameraman ve yönetmenin, yanlış bir şekilde, hareketli çekimlerin perdedeki aksiyonu hızlandırdığına inandığını; ancak bunun genellikle anlatılmak isteneni daha uzun bir sürede anlatması nedeniyle, tam tersine hikâyeyi yavaşlatıcı bir etkide bulunduğunu, uzun bir hareketli çekimden ise doğrudan kesmeyle birbirine bağlanan birkaç durağan kısa çekimin, yani kurgu yoluyla arttırılan ritmin çok daha iyi sonuç verdiğini belirtmektedir.

Benzeri bir amaçla, kahramanın zihnine ulaşılarak öznel ve daha derin bir anlatımın kullanıldığı durumlarda düşüncenin soyutluğunu ve eylemsizliğin getirdiği durağanlığı kırmak için kullanıır; psikolojik bir durumu, iç dünyada yaşanan gerilim ve çatışmaları yansıtmak adına tercih edilen bir araç olur zum. Ölmüş Bir Kadının Mektupları (Ülkü Erakalın, 1969)'nda Fikret (Hülya Koçyiğit)'in mektuplarının filmin başında kızı Nedret (Hülya Koçyiğit) tarafından okunması anında biri birini takip eden zum hareketleri kullanılmıştır. Yine aynı filmde Nejat (Ediz Hun)'ın barda otururken dış ses olarak izleyiciye aktarılan düşüncelerine dalması sırasında peş peşe zumlar gelir.

Ele alınan filmlerdeki zumlar çerçeveleme açısından belirgin bazı ortak özelliklere sahiptir. Yüzler çoğunlukla kompozisyonun merkezindedir. Yüze doğru yakınlaşan ya da yüzden geriye doğru zum en sık karşılaşılan kullanım şeklidir. Ardından yaygın olarak telefon, resim, yazı, tabak, çiçek, telefon, mektup, saat, daktilo vb. dekor öğeleri gelir. Bu kullanımı özellikle sahne açılış ve kapanışlarında daha çok tercih edilir. Hemen hemen her sahnenin zum ile açılması Yavrum'da bir alışkanlık haline gelmiştir. Zumun başlangıç ve bitiş çekim ölçekleri arası değişimi büyük, hızı yüksektir. Örneğin genel ya da boy çekimden yakın çekime - ya da tersi- yapılan ani zumlar yaygındır. Bir karşılaştırma yapılacak olursa bunlar, Visconti'ninMorte a Venezia (Venedik'te Ölüm, 1974)' de kullandığı yavaş ve dengeli zumların dışındadır. Ayrıca zum mizansen içindeki kameranın fiziksel hareketini de sınırlar. Böylece, tek bir kamera konumundan yapılan tek çekimle anlatım yoğunlaşır. Özellikle 1969' dan itibaren yaygınlaşan ve sıklaşan bu tipik zum kullanımına dair iyi bir örnek Şoför Nebahat (Süreyya Duru, 1969)'tır. Bu filmde yer yer çekim başına bir veya daha fazla sayıda zum düşer. Buna karşın zuma eşlik eden çevrinme harici diğer kamera hareketleri son derece sınırıdır. Yalnız kamera değil; mizansendeki oyuncu trafiğinin de belirgin bir biçimde kısıtlı olduğu dikkati çekmektedir.Bu durumu daha iyi kavrayabilmek ve film estetiğindeki dönüşümü görebilmek için birkaç yıl öncesinin zum içermeyen film diline bakmak yeterlidir.

\section{Zumdan Önce Mizansen}

1960’ların önemli bir kısmında dramatik anlardaki gerilim çoğunlukla ileri ya da geri kaydırma, oyuncu hareketi, yakın çekime kesme, çarpık çerçeveleme gibi yöntemler kullanılarak güçlendirilmekteydi. Ülkü Erakalın, Kucaktan Kucağa (1966) filminde böyle anları vurgulamak için sıkça oyuncunun çerçevede büyümesini tercih etmiş ve bu, genelde oyuncunun çevrinme eşliğinde kameraya yaklaşması ile ya da yakın çekim yüze yapılan hızlı kesmelerle sağlanmıştır. Benzer şekilde, Tehlikeli Adımlar (Mehmet Dinler, 1965)'da Haluk (Önder Somer), Semra (Hülya Koçyiğit)'nın itmesiyle düşüp başını demire vurduğunda bu beklenmedik an, yerde hareketsiz yatan adamın yüzüne doğru her biri daha yakın üç kısa çekimle (kesmeyle) vurgulanmıştır. Namusum İçin (Memduh Ün, 1966)'de Murat (Ayhan Işık)'ın karısını intihar etmiş bulduğu sahnede ve finaldeki çatışma sahnesinde, tek ya da arka arkaya hızıca yapılan kaydırma hareketleri ile gerilim artırımıştır. Yağmur Çiselerken (O. Nuri Ergün, 1967)'den verilebilecek bir örnekte ise Ekrem (Ekrem Bora), telefonda intihar haberini aldığında kamera yüzüne doğru hızla yaklaşır. Meleklerin İntikamı (Osman Seden, 1966)'nda Perihan (Türkan Şoray) evden kaçarken yatağın üzerine bıraktığı mektuba doğru kamera hızlı bir kaydırma hareketiyle yaklaşır. Finale doğru silahla ateş edildiğinde kapıdan giren adamın dehşete düşmüş yüzüne yine hızla yapılan 
kaydırma hareketiyle yaklaşıır. Garip Bir İzdivaç (Nejat Saydam, 1965)'ta, Zeynep (Türkan Şoray)'in evlatlık olduğunu öğrendiği anda yüzünün yakın çekimine varan bir kaydırma hareketi yapılır.

Zumun olmadığı ya da çok sınırlı kullanıldığı tüm örneklerde sözü edilen dramatik anlarda çevrinme hareketinin eşlik ettiği ileri/geri kaydırma hareketi sıkça kullanıır. Kamera yaklaşır, uzaklaşır, yine yaklaşır, yine uzaklaşır. İlerleyen yıllarda bu tarz çekimler zum ile yapılmaya başlanmıştır. Daha sonraki dönemlerde hemen hemen istisnasız ileriye/geriye zum hareketi ile vurgulanan duvardaki resme, yüze yakınlaşıp uzaklaşma, dramatik bir keşfediş, karşılaşma anları 1964'deki filmlerde kaydırma ile ifade edilmiştir. Anlaşılacağı üzere Yeşilçam sinemasında kaydırmanın kullanım amacı ve biçimiyle zumunki birbirine çok benzemekte; bu yönüyle de birinin kolayca diğerinin yerini almış olması şaşırııı görünmemektedir.

Buna karşın, zumun nadir kullanıldığı yıllardaki filmlerde yalnızca dramatik gerilim anlarında değil, iç mekân dâhil diyaloglu sahneleri de kapsayan, üçüncü boyutu ortaya çıkarmaya yarayan bol oyuncu ve kamera hareketinin varlığı dikkat çekicidir. Nitekim 1961 tarihli bir yazısında Nijat Özön (1995: 93) de genç yönetmenlerin üçüncü boyut yaratmanın önemini -her ne kadar yetersiz bulsa da- kavradıklarına değinir. Bu örneklerdeki mizansen planlaması uzun çekimlerde dinamik oyuncu ve kamera hareketi kombinasyonlarını içerir. Biraz daha yakından bakmakla bu filmlerin bir kısmında sahnelerin belirli bir incelikle tasarlandığı anlaşılabilir. Erkek ve Dişi (Halit Refiğ, 1966)'nin başlarındaki karakol sahnesinde polis memuru Burhan (Fikret Hakan) ve amiri (Reha Yurdakul) arasında geçen konuşmayı gösteren uzun çekimlerde oyuncular odayı boydan boya kat ederken kamera da onlarla birlikte konumunu değiştirir. Devingen kamera kullanımının daha iyi örnekleri Atçalı Kel Mehmet (AsafTengiz, 1964)'te bulunabilir. Atçalı (Fikret Hakan)'nın arkadaşı Çopur (Hayati Hamzaoğlu)'un esir tutulduğu ahırda eşkıya tarafından sorgulandığı sırada Atçalı tarafından kurtarımasını gösteren çekimde kamera ileri- geri kaydırma ve yay hareketleriyle bir yandan oyunculara yaklaşır, bir yandan da mekânı ve oyuncuların buradaki konumlarını izleyiciye yeniden hatırlatır. Benzer şekilde Tehlikeli Adımlar, Sevmek Zamanı (Metin Erksan, 1965), Son Kuşlar (Erdoğan Tokatlı, 1965) ve Ölüm Saati (Ertem Göreç, 1967) gibi filmlerde de kaydırma hareketi ve hareketli bir mizansen son derece yaygındır. Bunlar, söz konusu dönemin mizansenine dair verilebilecek çok sayıda örnekten yalnızca bir kaçıdır. Devingen bir mizansen yaratmak yalnız kamera değil, dekor yerleşimi, aydınlatma ve oyuncu hareketlerini de hesaba katan dikkatli bir trafiği gerektirmekte.

Öte yandan zumun çok sık kullanıldığı filmlerden biri olan Sevgili Babam (Aram Gülyüz, 1969)'da kaydırma hareketi nerdeyse ortadan kalkmış görünmektedir. Bu ve benzeri örneklerde zumun işlevi de değişmiştir. Yalnızca önemli anları imleyerek anlatıyı destekleyen bir araç olmaktan çıkarak her zaman ve her koşulda kullanılabilen bir hareket haline gelmiştir. Dramatik anlardaki bu zumlar, tekniğin sağladığı bir imkân olarak, kaydırma hareketinin yetişemeyeceği bir hızda yapılır. Zum, biçeme o kadar yayılmıştır ki, gerilim anlarını vurgulamak ancak daha kontrast bir zumla mümkün olmaktadır. Sevgili Babam'da bazı sahnelerde çekim başına bir zum hareketi düşmekte, hatta kimi zaman aynı çekim içinde ileri-geri zumlarla bu sayı daha da artmaktadır. Oysa aynı Aram Gülyüz, birkaç yıl önce zum hareketini sınırı tutarak daha çok kaydırmadan yararlanmaktaydı (Siyah Otomobil). Zumlar çevrinme ve kaydırma hareketleriyle birleştirilmekte; nadiren ve kaza, kavga, bir tehdidin vurgulanması gibi durumlarda kullanılmaktaydı. Üstelik aynı yıl çektiği bir başka film olan Gariban (1966)'da ise -eğer teknik bir engel yok ise- hiç zum kullanmamıştır.

Orhan Aksoy Kezban (1968)'da elinde zum gibi bir araç olmasına karşın ondan faydalanmakta 
aceleci davranmaz ve ancak filmin yarısından sonra gerilimin tırmandığı noktalarda zumu dâhil ederek sınırlı sayıda kullanır. Bu ve benzeri örnekler zum ve kaydırma hareketlerinin henüz başlarda yalnızca biri birine ikame olmaktan çok estetik bir tercih olduğunu düşündürmektedir. Başlangıçtaki bu daha ekonomik ve temkinli zum kullanımı dikkate değerdir.

Zumun yayılma aşamasının başlangıcında alışageldik bir teknik olarak kaydırma hareketi mizansenden hemen çıkarılıp atılmamış görünmektedir. Yönetmen zum kullandığı bir çekimin hemen ardından gelen çekimde kaydırma hareketi kullanabilir. Ah Güzel İstanbul (Atıf Yılmaz, 1966) çarpıcı anlarda kaydırma yerine ani zumları kullanan ilk filmlerden biridir. Haşmet (Sadri Alışık) derin düşüncelere dalmışken kamera yüzüne doğru yavaş bir hareket ile yaklaşırken, bir gürültü ile sıçradığında rahatsızığı sert bir geriye zum hareketi ile izleyiciye aktarıır. Filmin genelinde zumlar kimi zaman göze batmaları engellenmek istenircesine çevrinme hareketlerinin içine gizlenmiş; finale doğru Haşmet iş aramaya giderken ise esnafın şaşkın yüzüne doğru birer birer zum yapılmıştır. Böylece bunun bilinçli bir sinemasal tercih olduğu bir kez daha kendini gösterir. Aşk Bu Değil (Nuri Ergün, 1969)'de gazinocu (Turgut Özatay) ile Selma (Sema Özcan)'nın konuşmasına dinleyen kadın (Diclehan Baban)'ın irkilme anında ileri zum yapııırken; bir başka sahnede yaşlı kadının Selma'nın gazinoda çalışığını gazeteden öğrenişinde düştüğü şaşkınılı ileri kaydırma hareketiyle verilmiş olup zumun temkinli bir biçimde kullanılmasının bir diğer örneğidir.

\section{Sonuç}

Zum mercek ve buna bağlı olarak yapılan zum hareketi Yirminci Yüzyılın ilk yarısında ortaya çıkmış; ancak uzunca bir dönem sinemada nadir olarak kullanılmıştır. Zum, asıl teknik gelişimini ve bir efekt olarak yaygın kullanım alanını İkinci Dünya Savaşı sonrası özellikle televizyon yayıncıığının gelişimiyle ve stüdyo sistemi dışı bağımsız film yapımcılığının gelişimiyle kazandı. Yukarıda da belirtildiği gibi dünya sinema tarihinde zumun çok çeşitli ve yaratıcı kullanım örnekleri mevcuttur.

Zum mercek ve estetiği üzerine başlangıçta yapılan tartışmalar, daha çok onun teknik bir yenilik olarak bazı mekân sorunlarını aşma gibi film yapımında sağladığı kolaylıklara odaklanmıştır. ilerleyen yıllarda teknik gelişiminin tamamlanması ve kullanımının artmasına paralel olarak film diline getirdiği yenilik, sinemasal zaman ve mekân üzerindeki etkisi üzerine daha teorik düzeyde tartışmalara yönelinmiştir. Buna karşın, sinema yazınında zum henüz, örneğin bir uzun çekim kadar, incelenmemiş bir öğe olarak durmaktadır.

Türk sinemasında zumun yaygın bir biçimde kullanılması Batıdakinden bir miktar gecikmeyle de olsa, aşağı yukarı aynı tarihlerde, 1960 'ların sonundan itibaren ve 1970'lerde gerçekleşmiştir. Televizyonun zumun sinemada yayılmasında oynadığı rol hatırlanacak olursa; Türkiye'de Televizyon yayıncılığının gelişiminin daha geç gerçekleşmesi bu konudaki etkenlerden biri olabilir7. Ancak daha önemli bir etken zum hareketinin Batı sinemasında (örn. Yeni Hollywood sineması) yaygınlaşması ve daha dikkat çekici bir hal alması ile eşzamanlı olarak Türkiye'de yabancı film gösterimlerini takip eden sinemacıların dikkatini çekmiş olma intimalidir. Bu tür etkilenmeler bilinen bir gerçektir. Örneğin Kurosawa'nın Shichininnosamurai (Yedi Samuray, 1954) ve Ikimononokiroku ( I Live in Fear, 1955 ) filmlerindeki etkin kullanımı telefoto çekimlerinin sinemada popülerlik kazanmasında etkili olduğu (Bordwell, 1997: 246) söylenmektedir. Bu gibi etkilenmelerin yanı sıra, görüntü yönetmenlerinin film estetiğindeki etkisi ile yapım şirketlerinin sahip oldukları araç-gereçleri de hesaba katan gelecekteki araştırmalar, sinemamızın estetik tarihi yazılırken zumun yeri ve etkisini daha açık ve kapsamlı bir şekilde ortaya koyabilir.

7 Nitekim, TRT'nin televizyon yayınları 1968'de başlamıştır. 
İncelediğimiz filmlerde zum hareketi, vurgulama, tempoyu yükseltme, merak uyandırma, duygu ve düşünceleri somutlaşııma gibi sinemasal anlatım amacıyla kullanılmasının yanında devamlılık, çekim ve kurgu konularında da pratik nedenlerle tercih edilmiş görünmektedir. Başlarda zumun estetik ve temkinli bir kullanımı söz konusu iken bu çok kısa sürmüş, kullanıldığı filmlerde yönetmen ve kameramanlar tarafından hızla rağbet görmüştür. Aşırı kullanımı sonucu zum, etkisini ve değerini yitirmiştir. Bu nedenle sinemasal açıdan gerçekten intiyaç duyulduğu anlarda ancak daha keskin bir kullanımıyla görünür olmuştur.

Bir kısım filmde zum - kaydırma ayrımı düşüncesinin belirgin olduğu her iki tekniğin de ayrı ayrı kullanıımasından anlaşımaktadır. Zum bu filmlerde daha çok seyirci ya da karakter açısından bazı durumları vurgulamak için görsel bir efekt vazifesi görmektedir. Bu, sinema diline görsel bir katkı olarak nitelendirilebilir. Buna karşın, zumun yaygınlaşmasıyla birlikte bilinçli bir estetik tercihten çok kaydırma hareketine ikame ve hatta ondan daha cazip bir araç olarak görülmeye başlandığı açıktır. Bu ise biçemde kaçınılmaz olarak daha radikal bir değişikliği de beraberinde getirmiştir. Zumlarla birlikte mizansendeki kamera ve oyuncu hareketi azalmış; tek bir kamera konumundan yapılan tek çekimle anlatım yaygınlaşmışır. Önceki yılların sahnenin içinde yer alan, dolayısı ile seyirciyi sahnenin ortasına, olayların içine taşıyan kamerasının aksine zumun aşırı kullanımının bir sonucu olarak kamera sahnenin dışına itilmiş, olan biteni uzaktan seyreden teleskopik bir göze indirgenmiştir. Bununla birlikte, zum hareketi sadece kaydırma değil kesme yerine de kullanılan bir tür geçiş yani kurgu aracı haline de gelmiştir. Böylece etkisi mizansenin de ötesine uzanmıştır. Zum, Belton (1980)'ın da vurguladığı gibi, zamanı ve mekânı yeniden tanımlayarak yerleşik sinemasal kodları kırarak görmenin ve göstermenin yeni yollarını verebilecek bir ifade aracı iken, bir bütün olarak değerlendirildiğinde Yeşilçam sinemasında zumun aşırı kullanımı, film dilinde bir sığlaşma olarak kendini gösterir.1940'lardan1990'lara kadar Türk sinemasında üretim koşulları çok değişmemiştir (Atam, 2011: 29, 30, 36). Teknik olduğu kadar estetik bir yenilik olan zum, bu üretim koşullarının etkisi altında şekillenerek ona hizmet eden bir araç haline gelmiş, böylece film dilini geliştirmekten öte tam tersine onu gerileten bir işlev görmüştür.

Elimizdeki örneklerde Türk sinemasında yeni yeni gelişmeye başlayan, devinen bir mizansen anlayışının yerini, devinimi teknik bir araç olarak zumla sağlamaya çalışan durağan bir kamera ve mizansen almaktadır. Oysa zumun yaygın kullanıldığı filmlerin türleri, temaları, anlatı yapıları, mekânları ve süreleri zumun var olmadığı filmlerdekinden çok da farklı değildir. Artık yakın ya da çok yakın çekimden genel çekime ya da tam tersine zum hareketiyle geçilir. Kesmelerle bağlanan birden fazla çekim söz konusu değildir. Kalemi kâğıttan kaldırmadan yazılan bir el yazısını hatırlatırcasına farklı çerçevelemeler birbirine, çekim kesintiye uğratılmadan, zumla bağlanır. Bu çekim tekniğinin yazıda olduğu gibi filmi çekene ve kurgulayana hız kazandırdığı açık. Ancak, bu haliyle biçem, son derece özensiz, çalakalem karalanmış eskizler izlenimi uyandırır. Daha önce kesmeyle ve oyuncu/kamera hareketi ile sağlanan çerçeve değişimi zum ile sağlanmaya başlanmıştır. Bu, sinemasal bir sığlığı da beraberinde getirir ve önceki tasarımın nispeten zenginliği bu noktada ortadan kaybolmaya başlar. Bu hareket öylesine bir alışkanlık haline gelir ki, kamera bazı durumlarda adeta huzursuz bir şekilde, bir tik gibi, zum yapmadan duramaz. Tek bir hareketsiz çekim, akışkan olmayan sabit bir çerçeve bulmak zorlaşır. Bu tavır, Bordwell'in aktardığı araştıran, arayan bir kamera tavrından ve de Sarris'in bahsettiği soyutluğu somutlaştıran, devingen bir işlev gören hareket olmaktan çok uzak, hem nicelik hem de nitelik bakımından sömürüye dönüşen eskizci bir tavırdır. 


\section{Kaynakça}

Atam, Zahit(2011).Yakın Plan YeniTürkiye Sineması. İstanbul: Cadde.

Back, Frank G. (1947)."The Physical Properties and the Practical Applications of the Zoomar Lens”. Journal of Society of Motion Picture and Television Engineers. 49(1): 57-64.

Back, Frank G. ve Herbert, Lowen (1955). "Varifocal Lens Systemfor Motion Picture And Television Cameras". U.S. Patent No. 2718817 A.Washington, DC: U.S. Patent and Trademark Office.

Belton, John (1980).“The Bionic Eye: Zoom Esthetics”.Cineaste. 11(1): 20-27.

Bonitzer, Pascal (2011). Kör Alan ve Dekadrajlar. Çev., İzzet Yasar. İstanbul: Metis.

Bordwell, David (1997). On The History of Film Style.US: Harvard University.

Brown,Blain (2012).Cinematography: Theory and Practice. Imagemaking for Cinematographers, Directors \&Videographers. Oxford: FocalPress.

Gibbs, John (2011). "Thecry of the owl: investigating decision - making in a contemporary feature film". Movie: a Journal of Film Criticism. (3): 80-93.

Hall, Nick (2012).The Development and Use of the Zoom Lens in American Film and Television: 1946-1974. Yayımlanmamış Doktora Tezi. Exeter: University of Exeter.

Hall, Nick (2013). “Closer to the Action: Post War American Television and the Zoom Shot”. Television Aesthetics and Style.StevenPeacock, \& JasonJacobs (der.) içinde. London: Bloomsbury. 277-287.

Hall, Nick (t.y.)."Pierre Angenieux and The10: 1ZoomRevolution” http://www.zoomlenshistory.org.uk/whoinvented-the-zoom-lens/pierre-angenieux/.10.08.2014.

Hall, Nick (t.y.).“Who Invented The Zoom Lens?”.http://www.zoomlenshistory.org.uk/who-invented-the-zoomlens/10.08.2014.

Hayward, Susan (2000). Cinema Studies: Key Concepts. New York: Routledge.

Kırel, Serpil (2005). Yeşilçam Öykü Sineması.İstanbul: Babil.

Kingslake, Rudolph (1960). "The Development of The Zoom Lens". Journal of the SMPTE. 69 (8): 534-544.

Kingslake,Rudolph (1989). A History of thePhotographic Lens.San Diego: AcademicPress.

Mascelli, Joseph V. (1998).The FiveC's of Cinematography: Motion Picture Filming Techniques. Beverly Hills, CA: Silman-James.

O’Brien, Adam (2012)."When a Film Remembers Its filming: The New Hollywood Zoom". Journal of Media Practice. 13(3): 227-237.

Özön,Nijat (1963).Sinema Terimleri Sözlüğü.Ankara: Türk Dil Kurumu. 
Özön,Nijat (1995). “Üçüncü Boyut”.Karagöz’den Sinemaya: Türk Sineması ve Sorunları. Ankara: Kitle.

Salt,Barry (1977).“Film Style and Technology in theForties”.Film Quarterly. 31(1): 46-57. doi:10.2307/1211826.

Salt, Barry(1992). Film Style and Technology: History and Analysis. London: Starword.

Sobchack,Vivian (1990)."The Active Eye: A Phenomenology of CinematicVision".Quarterly Review of Film and Video. 12(3): 21-36.

Vineyard,Jeremy (2010). Sinemada Çekim Teknikleri: Her Sinemacının Bilmesi Gereken Kamera Hareketleri. Çev. Gökhan Rızaoğlu. İstanbul: İstanbul Organizasyon.

Wees, W. C. (1992).Light Moving in Time: Studies in the Visiual Aesthetics of Avant-Garde Film.Berkeley: University of California Press.

Willemen, Paul (2013).“The Zoom in Popular Cinema: A Question of Performance”. Inter-Asia Cultural Studies. 14 (1): 104-109.doi: 10.1080/14649373.2013.746774.

Değerli yorumları için hocam Prof. Dr. Nazlı Bayram'a teşekkür borçluyum. 